\title{
Are companies using Twitter to greenwash and hide bad environmental performance?
}

\author{
Thomas F. Johnson ${ }^{1,2} \cdot$ Matthew P. Greenwell ${ }^{1}$ \\ ${ }^{1}$ Ecology and Evolutionary Biology, School of Biological Sciences, University of Reading, Reading, UK \\ ${ }^{2}$ School of Biosciences, University of Sheffield, Sheffield, UK
}

Received: 17 August 2021/Revised: 8 December 2021 / Accepted: 14 December 2021/Published online: 15 January 2022 (C) The Author(s) 2022

\begin{abstract}
Companies and related consumer behaviours contribute significantly to global carbon emissions. However, consumer behaviour is shifting, with the public now recognising the real and immediate impact of climate change. Many companies are aware and seemingly eager to align to consumer's increasing environmental consciousness, yet there is a risk that some companies could be presenting themselves as environmentally friendly without implementing environmentally beneficial processes and products (i.e. greenwashing). Here, using longitudinal climate leadership, environmental messaging (Twitter) and stock price data, we explore how climate leadership (a relative climate change mitigation metric) and environmental messaging have changed for hundreds of UK companies. Using the environmental messaging, we also assess whether companies are simply greenwashing their true climate change performance. Finally, we explore how climate leadership and environmental messaging influence companies' stock prices. We found that companies (on average) have increased their climate leadership (coef: 0.14, CI 0.12-0.16) and environmental messaging (coef: 0.35 , CI 0.19-0.50) between 2010 and 2019. We also found an association where companies with more environmental messaging had a higher climate leadership (coef: 0.16, CI $0.07-0.26$ ), suggesting messaging was proportionate to environmental performance, and so there was no clear pattern of using Twitter for greenwashing across UK companies. In fact, some companies may be under-advertising their pro-environmental performance. Finally, we found no evidence that climate leadership, environmental
\end{abstract}

Thomas F. Johnson

Thomas.frederick.johnson@outlook.com messaging or greenwashing impacts a company's stock price.

Keywords Climate change - Corporate social responsibility · Environment - Finance · Greenwashing · Sustainability

\section{Introduction}

Climate change (IPCC 2014), biodiversity loss (IPBES 2019), and pollution (Rockström et al. 2009) are placing the planet under increasing stress. This environmental destruction and disturbance are already degrading the resilience of our economies and placing people's lives and livelihoods at risk (Bosello et al. 2006). In response, there have been calls from society (Han and Ahn, 2020), policymakers (United Nations 2018) and academics (Ripple et al. 2017) to shift the way humanity lives towards a more environmentally sustainable future.

Climate change and other environmental issues are not new problems, as they have been an area of concern within academic and policy circles for decades (Houghton et al. 1990). However, these issues have only gained widespread public concern in recent years (Leiserowitz et al. 2018), with evidence of an increase in people's environmental awareness and pro-environmental behaviours. For example, environmental protection rivals the economy as one of American citizens top concerns (Pew Research Center 2020), and people are increasingly avoiding single-use plastics (Ertz et al. 2017), switching to renewable energy (Ren21 2019) and embracing electric vehicles (International Energy Agency 2019). This shift in consumer behaviours towards greener (i.e. more environmentally 
conscious) purchasing is important as individual consumption can have negative implications on the environment (Stern 2000). There could be many reasons for this shift towards greener purchasing, ranging from concern for the environment, to conforming to new social norms-see White et al. (2019) for a review.

Beyond consumers, many companies are also striving to develop more environmentally sustainable practices and products (Allen and Craig 2016; Bonini et al. 2008). There are a variety of reasons for companies to become greener, ranging from an 'ecological responsibility' to mitigate environmental destruction and disturbance, through to a duty to abide by environmental legislation (Bansal and Roth 2000). But perhaps the most compelling, albeit narcissistic, justification for companies to become greener would be that improving environmental sustainability can offer a competitive advantage (Bansal and Roth 2000). For example, with an increasing shift towards environmental sustainability interests (Pew Research Center 2020), there is an opportunity for companies to meet the demand for greener products. Companies that are adapting to this newgreener demand are already absorbing more of the market share (Kronthal-Sacco and Whelan 2021) and performing better financially (Zhang et al. 2019). As a result, becoming more environmentally sustainable can be a good business decision (Fadul and Maurer 2004; Wagner and Schaltegger 2004).

Part of the improved economic performance by greener companies could be explained by consumers engaging more with companies that exhibit good social, environmental and ethical behaviour (El Zein et al. 2020). However, a company's sustainability performance information is at least partially opaque for consumers at the point of purchase, and so consumers are reliant on making purchasing decisions based in part on an item's branding (amongst other things). Given growing consumer interest in environmental sustainability (Pew Research Center 2020), it is reasonable to expect that companies will curate their brand image to appeal to consumers sustainability concerns. For consumers to effectively identify companies with sustainable practices, a company's branding would need to accurately represent the company's social and environmental performance. However, with a growing consumer interest in green products and a resulting economic benefit for green companies (El Zein et al. 2020), there is a risk to consumers that companies could use 'greenwashing' to over-represent their sustainability performance (de Freitas Netto et al. 2020).

Greenwashing - a type of disinformation used to describe ones actions as more environmentally friendly than the reality; see de Freitas Netto et al. (2020) for a review - could be advantageous for companies as they could reap the rewards of gaining environmentally conscious consumers without having to incur the costs of actually becoming more environmentally sustainable. The true extent of greenwashing by companies is unclear but could be high, as a report by the European Commission (2021) found $42 \%$ of claims (pro-environmental messages linked to products or websites) were likely to be false or misleading. For consumers, this may be problematic as they are purchasing items under false pretences that could violate their morals and beliefs, and for companies, beyond burdening themselves with violating people's morals, there could be a risk of being 'found out' and incurring reputational damage.

To prevent scenarios like greenwashing, many countries have marketing laws to ensure products are described fairly. For example, in the United Kingdom, it is illegal to falsely advertise products and deceive consumers (Gov 2008). These laws should protect consumers as companies are required to represent their products accurately, allowing a reasoned decision by the consumer about whether to buy or not. However, there are numerous high-profile incidences where these laws are stretched, or even ignored, e.g. the health impacts of smoking (Gilmore et al. 2015). Misrepresentations of this severity are likely rare, but misdirection may still pervade the issue of climate change and sustainability through greenwashing. For example, oil companies in the USA were more likely to advertise the environmental benefits of their products when the companies received media and governmental scrutiny (Brulle et al. 2020). This suggests that greenwashing was used as a mechanism to sway public opinion and legitimise their products, despite these products having high carbon outputs, i.e. using advertising as a public relations stunt to present the company as more environmentally sustainable than their sustainability actions deserve.

\subsection{Themes}

Companies are an important source of global carbon emissions (Ekwurzel et al. 2017), and whilst there is a desire from society (United Nations 2018) to address environmental problems, it is difficult to assess which companies are truly embracing more environmentally friendly practices, compared to those that are simply greenwashing. Here, combining data from social media and environmental performance disclosure projects, across hundreds of UK companies, we explore how environmental performance (Theme 1) and messaging (Theme 2) have changed over the last decade using a longitudinal analysis. We then consider if environmental messaging and performance are proportionate, or if there is a risk of greenwashing (Theme 3). Closing the work by exploring how the three above themes influence a company's financial performance (Theme 4). 


\subsubsection{Theme 1: Change in climate leadership}

If companies are listening to the societal (from people and policy) push towards a more environmentally sustainable future, we would expect companies' environmental performances to improve. We explore this theme by extracting climate leadership scores for hundreds of UK companies from the CDP (2020), where each score describes a company's relative adoption of strategies to mitigate climate change. We model timeseries of each company's climate leadership score to determine how climate leadership has changed over time across the sampled UK companies.

\subsubsection{Theme 2: Change in environmental messaging}

Given the increasing push from society towards a more sustainable carbon-neutral future (United Nations 2018), we would expect companies to have increased their environmental messaging. We explore this theme by extracting social media posts from Twitter over the past decade (2010-2019) for hundreds of UK companies and assess the changing frequency of environmental word use over time.

\subsubsection{Theme 3: Relationship between environmental messaging and performance}

Assuming that companies have implemented some climate change mitigation in response to the increasing recognition of climate impacts, we expect climate leadership and environmental messaging to have increased over time. However, we predict that some companies may not fully embrace pro-environmental behaviours, but will still try to obtain benefit from environmental messaging (greenwashing). If this is the case, we would expect no relationship between environmental messaging and climate leadership, or perhaps a clustered relationship, where some companies with high environmental messaging have high climate leadership, and a splinter group has high environmental messaging and low climate leadership. If companies are, on the whole, embracing pro-environmental behaviours, and accurately representing this in their brand, we would expect a clear positive relationship, where companies with high environmental messaging also have high climate leadership.

\subsubsection{Theme 4: Associations between financial performance, climate leadership and environmental messaging}

Evidence suggests that companies which develop more environmentally friendly products are taking more of the market share (Kronthal-Sacco and Whelan, 2021) and becoming more profitable (Zhang et al. 2019). We propose three potential mechanisms for this improved financial performance: (1) Becoming more environmental creates a competitive advantage (Bansal and Roth 2000); (2) Promoting environmentally friendly products and processes expands a consumer base by attracting environmentally conscious consumers (Zhang et al. 2019) and can attract investors (Albarrak et al. 2019). (3) However, if option 2 is utilised without also applying option 1 , there is also a risk of reputational damage from greenwashing and the resulting financial consequences (de Jong et al. 2020). We explore these scenarios by modelling stock price growth rates for companies against climate leadership scores (1), environmental messaging frequency (2), and a greenwashing proxy variable (3), all with the aim of understanding potential influences on financial performance.

\section{Research methodology}

\subsection{Data}

\subsubsection{CDP data}

We obtained climate change performance data from the publicly available CDP (formerly known as the Carbon Disclosure Project) companies dataset (CDP 2020). Globally in 2019 , over 8,400 companies disclosed their environmental performance information, which falls into three themes with descending degrees of available data ( $\mathrm{N}$ represents number of disclosing companies in each category): climate change $(\mathrm{N}=8361)$, water security $(\mathrm{N}=2435)$, and forests $(\mathrm{N}=543)$. Here, we focus solely on climate change, as it is the most populated theme and has been collected for a selection of companies as far back as 2003 (CDP, 2020). The publicly available CDP dataset provides an ordinal summary score for each company in each year, ranging from $\mathrm{A}$ to $\mathrm{D}$, with intermediate minus scores (e.g. A-) in between: A represents 'leadership', B is 'management', $\mathrm{C}$ is 'awareness', and $\mathrm{D}$ is 'disclosure'. Such that, an A company would be one of the 'world's most pioneering companies leading on environmental transparency and performance', whilst a D company is participating in the disclosure but is not a leader in addressing environmental risks. Earlier in the scheme, there was also a category E which has now been removed by the CDP from the scoring - to standardize scoring across the dataset, we removed all E's. To simplify this ordinal scale and allow averaging over years, we converted this into a numeric integer scale-as has been done in previous work (Guo et al. 2020)—ranging from 8 to 1 , where $\mathrm{A}=8, \mathrm{~A}-=7, \mathrm{~B}=6$, $\mathrm{B}-=5$, and so forth up to $\mathrm{D}-\mathrm{=} 1$. In cases where a company had provided insufficient information to be assessed, or had been asked to participate in the disclosure by an 
investor or customer, but failed to complete the disclosure, the company is granted an F. We classed these F scores, as well as a series of additional categories with similar sentiment, as missing values.

We obtained the names of all UK registered companies that participated in the 2019 CDP disclosures $(\mathrm{N}=510)$ and extracted the climate scores for each company, going back to 2010. We excluded the CDP data between 2003 and 2009 as during this period few companies participated in disclosures and many companies lacked Twitter profiles (see below). Each of the 510 UK companies listed in the CDP fell into one of 13 sectors. Some sectors only contained one company, so these smaller sectors were consolidated into other relevant groups. Specifically, 'Transport OEMS' was merged with 'Transport services', the 'Steel' and 'Cement' sectors were placed in 'Construction', and any companies with missing sector information were placed in the 'General' category. The number of companies falling in each sector was highly variable (Fig. 1a), and more than $80 \%$ of companies were in the 'General' category, which could occur when companies don't align to any specific sector. The proportion of companies disclosing in each sector varied considerably, with $86 \%$ of agricultural commodity companies missing climate scores in at least eight of the last 10 years, whilst in food, beverage and tobacco, only $15 \%$ of companies were missing values (Fig. 1a). The proportion of missing values also varied over time; by extracting all publicly available climate change scores dating back to 2010, we observed a general trend towards fewer missing values in recent years (Fig. 1b). One concern with these missing values is that companies failing to disclose could have lower climate scores (Dawkins and Fraas, 2011). There is no means of detecting whether these biases are present, but we characterise the distribution of scores across time and sectors (Fig. 1; Figure S1-2). a

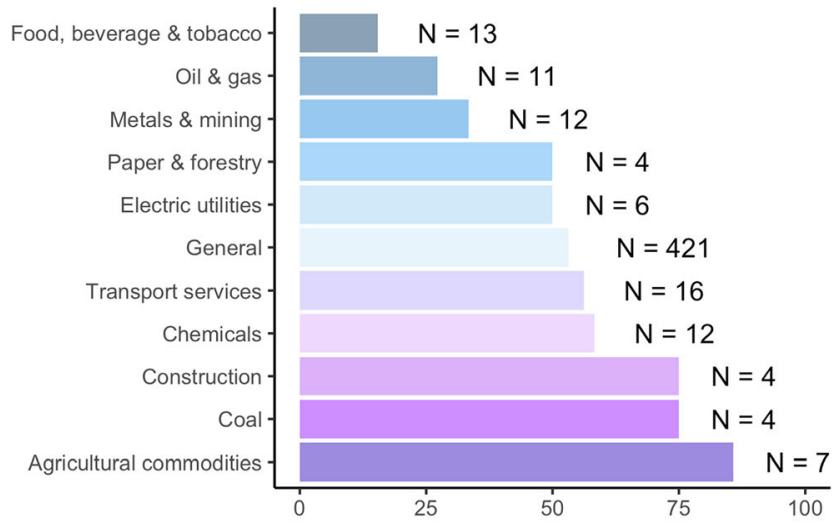

C
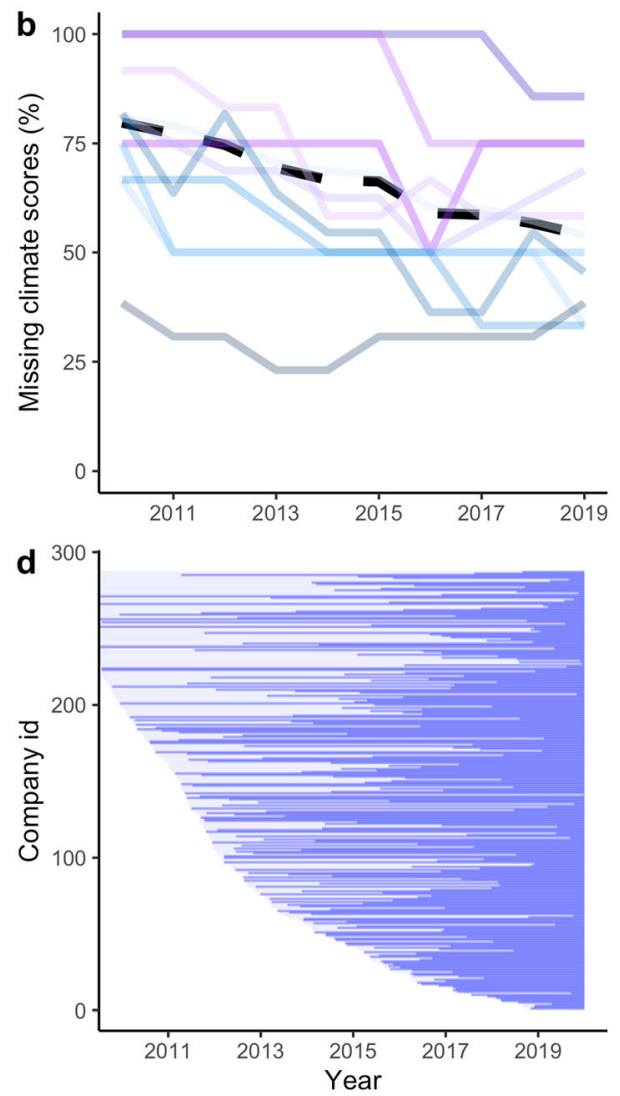

Fig. 1 a Percentage of companies in each sector with less than two climate leadership scores, labelled with accompanying total (with and without missing data) number of companies $(\mathrm{N})$ in the sector. b Change in missing climate scores (\%) per sector between 2010 and 2019. The black dashed line represents the average across all sectors. c Mean $( \pm 1$ standard deviation) climate score per sector against missing climate scores. Black line and the accompanying grey ribbon
( $95 \%$ confidence intervals) represent a linear model between the mean climate score and missing climate scores. d Each horizontal line represents a company with an account on Twitter, and the left-point on each line indicates the account opening date. Tweets that fell within the last 3200 of each account were downloaded and are indicated in blue, whilst grey indicates the period where tweets were unavailable (missing values) 


\subsubsection{Twitter data}

For each of the 510 UK companies listed in the CDP, we manually searched for their Twitter handle (profile). Some companies had multiple handles for different aspects of their company, and in these cases, we always selected the account that most closely represented the UK arm of the business. There were also some accounts where it was uncertain if we had identified the correct Twitter handle, and so we removed these accounts from the dataset. After this step, we were left with 287 companies, and we downloaded (on May $22^{\text {nd }} 2020$ ) each companies last 3,200 (the limit set by Twitter) tweets using the 'rtweet' $\mathrm{R}$ package (Kearney 2017). These tweets were all in the public domain. For some companies, the 3200 tweets stretched beyond 2010 (over 10 years) and covered their entire history on Twitter. Whilst for other companies, tweets only stretched back a matter of months and missed much of these companies' historic tweets (Fig. 1d).

With this Twitter timeseries dataset, we identified all tweets which contained any of the following environmental terms: climate, temperature, global warming, sustainable, sustainability, nature, renewable, carbon neutral, flood, drought, desertification, ocean acidification, coral bleaching, and wildfire. It is worth noting that some of these terms are only tangential to the topic of climate change, unlike the CDP climate score, but were specifically selected so we could capture companies talking about the potential impacts (e.g. wildfire) or mitigation strategies (e.g. renewable) of climate change. Notably, environmental terms are not strictly indicators of pro-environmental messaging, as a company could discuss the environment as a bad thing-e.g. 'this push to renewables is a pointless waste of money'-although we suspect incidences of environmental criticism to be rare given rising environmental interests (Pew Research Center 2020).

\subsubsection{Stock prices}

We searched for stock prices from the London Stock Exchange for all companies with at least two years of climate and Twitter data $(\mathrm{N}=128)$ using the 'BatchGetSymbols' R package (Perlin 2020). Thirty-four companies were not listed on the London Stock Exchange, and so we removed these from the dataset. Three further companies (Kingfisher, St James Place and Taylor Wimpey plc) had incomplete stock histories so were also removed. For each company, we extracted the mean adjusted closing stock price for each year to produce an annual time series of stock prices. The adjusted closing stock price was used, as stock value can be influenced by dividends, stock splits, and new stock releases (e.g. changes in stock volume), which would be accounted for in the adjusted stock closing price.

\subsection{Models}

\subsubsection{Change in climate leadership}

To assess how climate leadership changed over time (Theme 2), we developed a linear mixed effect model, with climate score as the response ranging from 1 to 8 , and included 'years since 2010' as a predictor. Initially, we also included company name as a random intercept and correlated-slope, nested within another random intercept and correlated-slope of company sector (as specified by the CDP). This random intercept and slope allows a linear model of climate score against 'years since 2010' to be fit for each company and nested-sector, and controls for variable slopes within the hierarchical structure. However, we opted to remove the random slope element from the model as a simpler random intercept model had a substantially lower Akaike information criterion (intercept and slope AIC $=6262$, whilst intercept only AIC $=6165$ ). As a result, in our final model, companies and sectors were all fit with the same slope but varying intercepts. The results we present in main text represent the 'change in climate leadership model' using all available data $(\mathrm{N}=510)$, but in the supplementary, we also provide identical outputs for this model using the smaller more complete sample of data $(\mathrm{N}=86)$ used in the structural equation modelling (models $1-5$ below).

Conventionally, the ordinal data behind the above models should be handled with an ordinal model, but in later models (see 'Link between climate leadership, environmental messaging, and stock prices'), this rank is summarised into a temporal trend and an average rank, which are both more easily interpreted when the score is treated as a continuous number. As a result, for consistency across this work, we treat climate leadership as a continuous variable throughout. However, this does have implications for interpretation, as reclassifying our ordinal to an integer-scale means a jump in one letter classification jumps an integer. For example, moving from $\mathrm{D}$ - to $\mathrm{D}$ is the equivalent of jumping from 1 to $2-$ a doubling. Further, our classification assumes a company that scores an A has eight times greater climate leadership than a company that has scored D-. It is unclear whether this is a fair assumption, and so we advise our climate leadership results to be interpreted with caution. However, to ensure our inference is valid, we also repeated the 'change in climate leadership' test with an ordinal model in the supplementary material, referred to in the results section.

Finally, to determine which sector generally has the best climate governance, we averaged (mean) the climate 
Table 1 Variables and their accompanying description used within the structural equation modelling

\begin{tabular}{|c|c|}
\hline Variable & Description \\
\hline Climate leadership score & $\begin{array}{l}\text { Mean climate leadership score of a company across all available years. This averaging is over the numeric } \\
\text { representation of the scores where A is high (8) and D- is low (1) }\end{array}$ \\
\hline $\begin{array}{l}\text { Annual change in climate } \\
\text { leadership score }\end{array}$ & Slope coefficient from a log-linear regression of the annual numeric climate leadership score against year \\
\hline $\begin{array}{l}\text { Annual change in environmental } \\
\text { messaging }\end{array}$ & Slope coefficient from a log-linear regression of annual environmental messaging (\%) against year \\
\hline Greenwashing index & $\begin{array}{l}\text { Residuals from a linear model with environmental messaging as the response and climate score as the } \\
\text { predictor }\end{array}$ \\
\hline Environmental messaging & Mean environmental messaging $(\%)$ across all available years \\
\hline Annual change in Stock prices & Slope coefficient from a log-linear regression of adjusted closing stock prices against year \\
\hline Followers & $\begin{array}{l}\text { A company's number of followers on Twitter (as of May 22nd 2020), acting as a proxy for how public-facing } \\
\text { a company is }\end{array}$ \\
\hline
\end{tabular}

Each variable is the company level

leadership scores across all years and companies within each sector.

\subsubsection{Change in environmental messaging}

To determine the change in environmental messaging (Theme 2), we used a logistic mixed model, with a binary value indicating whether each tweet contained any of the specified environmental terms. We modelled this response against 'years since 2010' and included company name as a random intercept and correlated-slope, nested within another random intercept and correlated-slope of company sector (as specified by the CDP), as described in the 'change in climate leadership model'. The results we present in the main text represent the 'change in environmental messaging model' using all available data $(\mathrm{N}=287)$, but in the supplementary, we also provide identical outputs for this model using the smaller more complete sample of data $(\mathrm{N}=86)$ used in the structural equation modelling (models $1-5$ below).

As an accompaniment to the environmental messaging model, we also characterised the overall word use, identifying the 150 most used words across UK companies' Twitter profiles (see Table S1). As part of this, we removed all punctuation and numbers (Johnson et al. 2021b), and then stemmed words (e.g. 'consulting' and 'consultation' would both become 'consult'). Finally, we removed all stop words (e.g. common words like 'the' and 'a') specified by the 'tm' R package (Feinerer and Hornik 2019).

\subsubsection{Link between climate leadership, environmental messaging, and stock prices}

For each company, in each of the last 10 years (2010-2019), we derived the mean climate leadership score, percentage of environmental tweets, and the mean adjusted closing stock price. We averaged the finer temporal resolution tweet and stock data to an annual value to match with the temporal extent of the climate leadership score. This averaging allows us to detect broad-scale patterns but is unsuitable for exploring the variation around fine-scale volatility. After averaging, we removed all years with any missing values, and all companies which had less than two years of complete data. In the remaining companies $(\mathrm{N}=86)$, we derived six variables-see Table 1 . We also extracted the number of Twitter followers for each company, to act as a proxy for how public-facing a company is, i.e. is this company reliant on a good relationship with the public for sales.

We developed five linear mixed-effect models within a piecewise structural equation framework to explore climate leadership, environmental messaging, and stock prices. We present simplified equations for all five models below, where $y$ is the response, $\alpha$ is the intercept, $\beta$ is the fixed effect coefficient for a variable contained within brackets, $\mu$ is the random intercept term nesting companies within sectors (controlling for sector-specific variation), and $\varepsilon$ is the error term of a Gaussian linear model:

\section{Model 1}

$y \sim \alpha+\beta_{1}(\text { Followers })_{i j}+\mu_{j}+\varepsilon_{i j}$

In Model 1, we assess if more public-facing companies have higher climate leadership scores by regressing the climate leadership score (response) against a company's number of Twitter followers.

\section{Model 2}

$$
\begin{aligned}
y & \sim \alpha \\
& +\beta_{1}(\text { Followers })_{i j}+\beta_{2}(\text { Climate leadership score })_{i j}+\mu_{j} \\
& +\varepsilon_{i j}
\end{aligned}
$$

In Model 2, we search for the presence of greenwashing by comparing how a company's environmental messaging 
is related to their climate leadership score, specifically, regressing environmental messaging (response) against climate leadership score. To observe strong evidence of greenwashing across UK companies, we would expect to observe no association between environmental messaging and climate leadership scores, whereas a positive association would indicate environmental messaging is greater in companies with higher climate leadership (relates to Theme 3-see above). Within model 2, we also control for Twitter followers, as we may expect more public-facing companies to promote environmental messaging more regularly.

\section{Model 3}

$$
\begin{aligned}
y & \sim \alpha \\
& +\beta_{1}(\text { Followers })_{i j}+\beta_{2}(\text { Climate leadership score })_{i j}+\mu_{j} \\
& +\varepsilon_{i j}
\end{aligned}
$$

In Model 3, we investigate how the rate of growth in climate leadership is influenced by how public-facing a company is, regressing change in climate leadership score (response) against number of followers, whilst controlling for the mean climate leadership score which could confound this result. We would expect more public-facing companies to exhibit a faster growth in climate leadership.

\section{Model 4}

$$
\begin{aligned}
y \sim \alpha & +\beta_{1}(\text { Followers })_{i j}+\beta_{2}(\text { Climate leadership score })_{i j} \\
& \left.\beta_{3} \text { (Environmental messaging }\right)_{i j} \\
& +\beta_{4}(\text { Annual change in climate leadership score })_{i j} \\
& +\mu_{j}+\varepsilon_{i j}
\end{aligned}
$$

In Model 4, we asses if the rate of change on environmental messaging is associated with the rate of change in climate leadership, where we would expect companies with a faster push towards high climate leadership to also have a faster increase in their environmental messaging. Specifically, we regressed change in environmental messaging (response) against change in climate leadership, controlling for mean climate leadership and mean environmental messaging - both possible confounders. We also included number of followers as a predictor in this model, as we may expect more public-facing companies to have a faster growth in environmental messaging.

\section{Model 5}

$y \sim \alpha+\beta_{1}(\text { Greenwashing index })_{i j}$

$+\beta_{2}$ (Annual change in environmental messaging $)_{i j}$

$+\beta_{3}$ (Annual change in climate leadership score $)_{i j}+\mu_{j}+\varepsilon_{i j}$

In Model 5, we assess the implications of a change in climate leadership, change in environmental messaging, and greenwashing, all on a company's stock performance, where we expect an increase in climate leadership and environmental messaging offers potential financial gain (El Zein et al. 2020). However, the implications of greenwashing on stock performance are likely complex (refer to Theme 4-see above), with greenwashing offering the potential for accelerated growth, alongside public relations backlash. We explore these questions by regressing the change in a companies' stock prices (response) against the change in climate leadership score, change in environmental messaging, and the greenwashing index.

To meet model assumptions of normal residuals across the five models, we added $0.1 \%$ to mean environmental messaging in model 2 and then log transformed (base 10) the variable, dealing with companies that never produced an environmental tweet; we present the back-transformed values in marginal effects plots within the results. The only model assumption we failed to meet was within model 3, where the variance of the residuals was heterogenous as companies with high climate leadership scores had a lower change in their scores. This heterogeneous error is captured in the marginal effect plots.

\section{Results}

\subsection{Change in climate leadership}

In the UK, climate leadership has increased since 2010 (coef: 0.14, CI $0.12-0.16, \mathrm{~N}=510$, Fig. 2a), with companies improving by a grade (e.g. B to A-) every 7.1 years, on average. These results are largely mirrored when the model was re-ran on the smaller more complete fragment of data used in the structural equation modelling, where a grade increased every 6.25 years (coef: 0.16 , CI $0.13-0.19$, $\mathrm{N}=86$ ). Further, modelling change in climate leadership within an ordinal model also showed a general trend towards increasing scores over time (Fig. S3). Despite clear evidence of an increasing trend, not all of the 510 companies showed an increase, with a stable climate leadership in $8.7 \%$ of companies, and declining leadership in $29.3 \%$. All sectors had a comparable growth in climate leadership (evidenced by the improved fit of removing random slopes-see Research methodology), but highly variable intercepts $\left(\mathrm{R}^{2}\right.$ marginal: $0.04, \mathrm{R}^{2}$ conditional: 0.55$)$, indicating sectors have started climate leadership growth from different positions. When averaging climate leadership across sectors, electric utilities came out as the best performing, whilst construction was the worst performing (Table 2). 


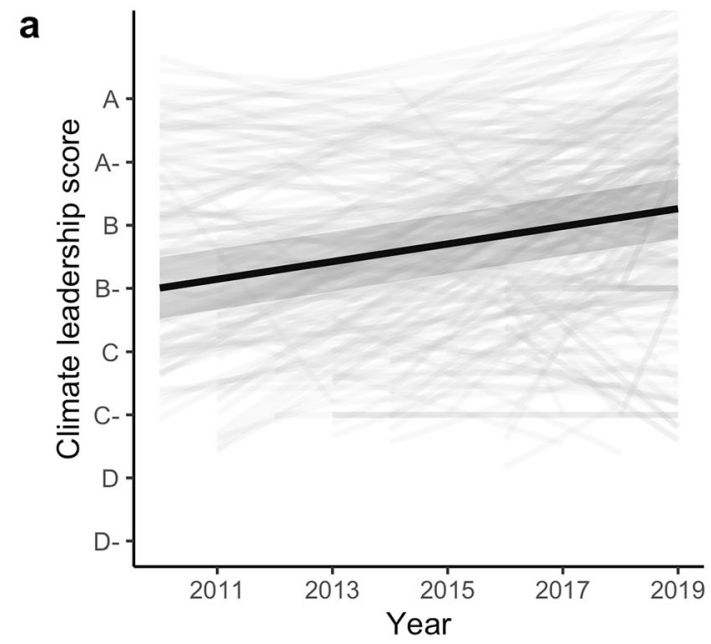

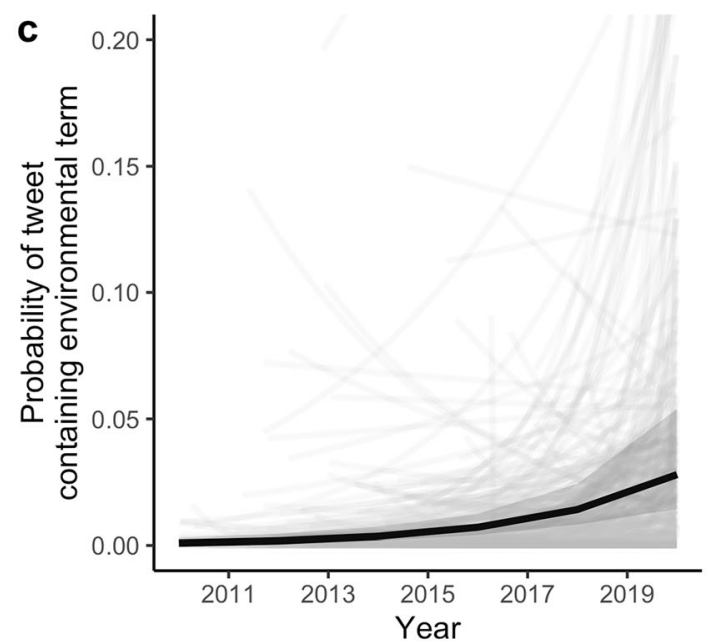

Fig. 2 a Each light grey line represents a company (with two or more climate leadership scores) and shows the change in climate leadership scores over time through a linear regression. The black line and accompanying grey ribbon (95\% confidence intervals) indicate the average change in climate leadership scores across all companies. For the outputs of an equivalent model, but with an ordinal instead of a continuous response, see the supplementary material. b 150 most used

\subsection{Change in environmental messaging}

Only one word broadly related to the environment ('sustain') was found in the 150 most used words across all tweets (Fig. 2b), which underlines the rarity of these environmental messages (Fig. 2c). However, environmental messaging did increase over time, both within the 510 sample of companies (coef: 0.35 , CI $0.19-0.50, \mathrm{R}^{2 \text { marginal }}$ : $0.07, \mathrm{R}^{2 \text { conditional }}: 0.53$ ), and in the smaller 86 sample (coef: 0.38, CI $0.28-0.48, \mathrm{R}^{2 \text { marginal }}: 0.09, \mathrm{R}^{2 \text { conditional }}: 0.43$ ). This growth was from a position of almost no environmental messaging, where on average across all 510 UK companies, the probability of tweets containing an environmental term was less than 0.001 in 2010 , increasing to 0.03 in 2019. However, this growth was highly variable across words across all tweets and years (after removing stop words, e.g. 'the'), with terms broadly related to the environment indicated in bold dark-green (see 'sustain'). Word size is proportionate to frequency. c Each light grey line represents a company and shows the change in environmental messaging over time through a logistic regression. The black line and accompanying grey ribbon (95\% confidence intervals) indicate the change in environmental messaging across all companies

sectors, with the slowest growth in construction, and fastest growth in electric utilities (Table 2). Paper \& forestry was the sector with the most environmental messaging across companies and years.

\subsection{Link between climate leadership, environmental messaging, and stock prices}

In Model 1 of the piecewise structural equation model (see Table 3 and Fig. 3), we observed a positive association between number of followers and climate leadership, with a good model fit primarily driven the fixed effect of followers (high marginal $\mathrm{R}^{2}$ ). In model 2, number of followers was not associated with environmental messaging, but we did observe a positive association between climate 
Table 2 CDP sector summaries, with columns from left to right describing: sector name; the mean climate leadership score across all companies and years within each sector, with the standard deviation in brackets and $\mathrm{N}$ represents the number of $\mathrm{CDP}$ scores within the sector; the proportion of tweets containing environmental messaging terms across all companies and years within each sector, with the standard deviation in brackets and $\mathrm{N}$ represents the number of tweets within the sector; and finally, the annual rate of change in environmental messaging in each sector, derived from the random slopes in the 'Change in environmental messaging' model

\begin{tabular}{llll}
\hline Sector & Climate leadership & Environmental messaging—mean & Environmental messaging-rate of change \\
\hline Electric utilities & $7.7(1.1) ; \mathrm{N}=30$ & $0.04(0.20) ; \mathrm{N}=8469$ & 0.66 \\
Coal & $7.1(1.5) ; \mathrm{N}=11$ & $0.04(0.18) ; \mathrm{N}=2470$ & 0.36 \\
Paper \& forestry & $6.6(1.7) ; \mathrm{N}=19$ & $0.11(0.31) ; \mathrm{N}=2656$ & 0.48 \\
Food, beverage \& tobacco & $6.2(2.1) ; \mathrm{N}=90$ & $0.05(0.22) ; \mathrm{N}=10,407$ & 0.27 \\
Transport services & $6.2(1.4) ; \mathrm{N}=55$ & $0.01(0.10) ; \mathrm{N}=15,661$ & 0.34 \\
Agricultural commodities & $6.0(1.4) ; \mathrm{N}=2$ & $0.04(0.20) ; \mathrm{N}=2000$ & 0.22 \\
General & $5.8(1.7) ; \mathrm{N}=1370$ & $0.01(0.12) ; \mathrm{N}=350,882$ & 0.28 \\
Chemicals & $5.7(1.7) ; \mathrm{N}=35$ & $0.02(0.15) ; \mathrm{N}=1663$ & 0.47 \\
Metals \& mining & $5.5(1.5) ; \mathrm{N}=59$ & $0.03(0.18) ; \mathrm{N}=6367$ & 0.21 \\
Oil \& gas & $4.8(1.6) ; \mathrm{N}=47$ & $0.05(0.22) ; \mathrm{N}=4566$ & 0.37 \\
Construction & $4.0(1.2) ; \mathrm{N}=4$ & $0.02(0.14) ; \mathrm{N}=3527$ & 0.18 \\
\hline
\end{tabular}

Table 3 Structures and outputs from the piecewise structural equation models

\begin{tabular}{|c|c|c|c|c|}
\hline Models & coef & $95 \% \mathrm{CI}$ & $\mathrm{R}^{2 \mathrm{~m}}$ & $\mathrm{R}^{2 \mathrm{c}}$ \\
\hline 1. Climate leadership score ${ }_{i j} \sim$ & & & 0.36 & 0.42 \\
\hline $\mathrm{b}_{1}$ Followers $_{\mathrm{ij}}$ & 1.12 & $0.82,1.46$ & & \\
\hline 2. Environmental messaging $\mathrm{ij}_{\mathrm{j}} \sim$ & & & 0.13 & 0.15 \\
\hline $\mathrm{b}_{1}$ Followers $_{\mathrm{ij}}$ & -0.07 & $-0.24,0.10$ & & \\
\hline $\mathrm{b}_{2}$ Climate leadership score ${ }_{i j}$ & 0.16 & $0.07,0.26$ & & \\
\hline 3. Change in climate leadership score ${ }_{i j} \sim$ & & & 0.06 & 0.06 \\
\hline $\mathrm{b}_{1}$ Followers $_{\mathrm{ij}}$ & -1.21 & $-3.80,1.35$ & & \\
\hline $\mathrm{b}_{2}$ Climate leadership score ${ }_{i j}$ & -0.92 & $-2.29,0.64$ & & \\
\hline 4. Change in environmental messaging ${ }_{\mathrm{ij}} \sim$ & & & 0.07 & 0.60 \\
\hline $\mathrm{b}_{1}$ Followers $_{\mathrm{ij}}+$ & -2.25 & $-15.7,9.52$ & & \\
\hline $\mathrm{b}_{2}$ Climate leadership score $\mathrm{ij}_{+}$ & 2.02 & $-5.41,9.33$ & & \\
\hline $\mathrm{b}_{3}$ Environmental messaging $\mathrm{ij}_{+}$ & 22.7 & $9.15,38.0$ & & \\
\hline $\mathrm{b}_{4}$ Annual change in climate leadership score ${ }_{i j}$ & 0.19 & $-0.72,1.27$ & & \\
\hline 5. Change in stock price $e_{i j} \sim$ & & & 0.02 & 0.50 \\
\hline $\mathrm{b}_{1}$ Greenashing index $\mathrm{x}_{\mathrm{ij}}$ & -0.20 & $-1.33,0.93$ & & \\
\hline $\mathrm{b}_{2}$ Annual change in climate leadership score ${ }_{\mathrm{ij}}$ & 0.07 & $-0.39,0.52$ & & \\
\hline $\mathrm{b}_{3}$ Annual change in environmental messaging $\mathrm{ij}_{\mathrm{j}}$ & -0.06 & $-0.16,0.02$ & & \\
\hline
\end{tabular}

The predictors of the five models are indented, and we do not show the intercept $\left(b_{0}\right)$, random intercept $\left(\right.$ Sector $\left._{i}\right)$, or Gaussian error terms (error ${ }_{i j}$ ) in the models. For each predictor, we show the slope coefficient (coef) and 95\% confidence intervals (95\% CI), which were derived from 1000 bootstrap simulations. Predictors with an effect at the $95 \%$ confidence interval are depicted in bold. For each model, we report the marginal $\left(\mathrm{R}^{2 \mathrm{~m}}\right)$ and conditional $\left(\mathrm{R}^{2 \mathrm{c}}\right) \mathrm{r}$-squared leadership and environmental messaging, albeit with a moderate model fit. In model 3 , neither number of followers nor climate leadership were associated with the change in climate leadership, with a poor model fit. In model 4 , the only important covariate was environmental messaging, where companies with more environmental messaging have shown a greater growth in messaging. This effect was not linear, with a strong clustering in the data (Fig. 3c). Whilst model 4 had a good fit, with a conditional $\mathrm{R}^{2}$ of 0.6 , this fit was driven by controlling for sector-specific intercepts, as the marginal $\mathrm{R}^{2}$ was low. In model 5, none of the covariates had an effect on stock prices, but the model had a good fit, again driven by sectorspecific intercepts. 


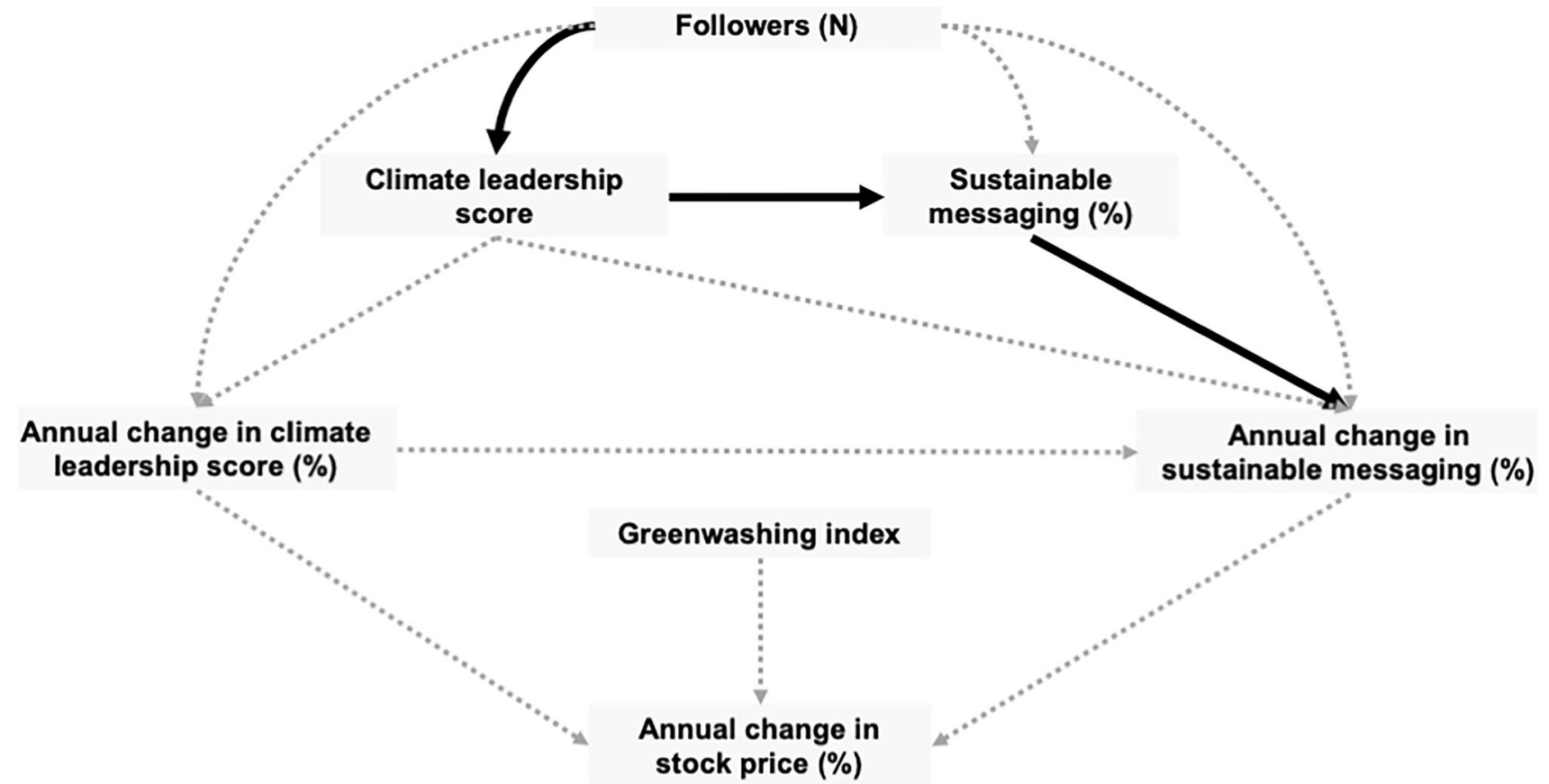

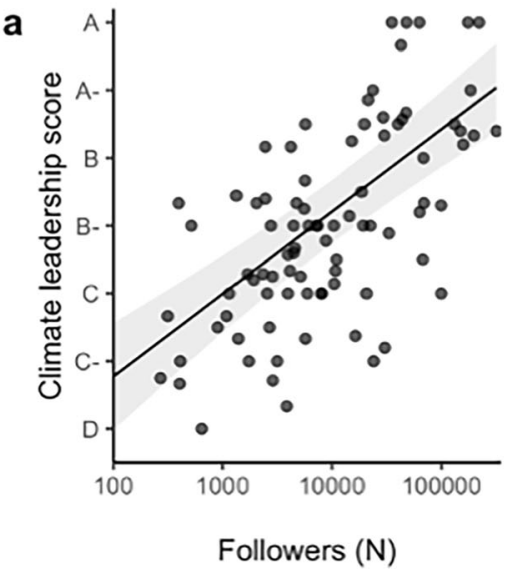

Fig. 3 Piecewise structural equation model describing effect of predictors (base of arrows) on responses (tips of arrows). Black arrows indicate a significant effect, whilst grey arrows indicate no effect, both at the $95 \%$ confidence interval-level. Refer to Table 3 for

\section{Discussion}

We explored how climate leadership and environmental messaging on Twitter have changed across UK companies and assessed if environmental messaging is simply a form of greenwashing to attract consumers under the guise of environmentally friendly practices. We found evidence that climate leadership and environmental messaging have increased in the last 10 years (Fig. 2) and found that companies with a larger number of followers had higher climate leadership, but followers had no effect on environmental messaging (Fig. 3). This is partly encouraging, as more public-facing companies (those with more effect sizes. a-c Describe the marginal effects and $95 \%$ confidence intervals of significant effects in the structural equation model, with all other variables held at their mean. The points in $\mathbf{a}-\mathbf{c}$ are the raw values

followers) appear to be truly embracing climate leadership instead of simply increasing environmental messaging to appease their consumers. The downside to this is that generally, less public-facing companies have a lower climate leadership. In contrast, growth in environmental messaging was greater in companies that already had a high mean environmental messaging. There was no relationship between the change in environmental messaging and change in climate leadership. However, we did find a positive relationship between mean climate leadership and environmental messaging, suggesting companies are promoting their climate leadership performance fairly on Twitter (at least relative to one another). Although there are 
some exceptions here, as some companies still regularly release environmental messages despite having low climate leadership.

In general, environmental messaging on Twitter was greater in companies with higher climate leadership scores, suggesting that companies are promoting genuine efforts to be more environmentally sustainable-not simply greenwashing. These findings largely agree with a case study on Australian companies, where no greenwashing was detected in companies showing improved environmental performance; although 'potential greenwashing' was present amongst bad environmental performers (Wedari et al. 2021). Furthermore, as the number of followers had no effect on environmental messaging, but did positively impact climate leadership, it appears that public-facing companies are truly embracing pro-environment behaviours, instead of just pandering to their many followers. However, the fixed effects only contributed a relatively small amount to the model fit (low marginal $\mathrm{R}^{2}$ ) and some companies far exceeded their expected environmental messaging, i.e. low climate leadership but high environmental messaging. In these cases, it may be reasonable to suggest these companies are over promoting their actions through greenwashing-again agreeing with (Wedari et al. 2021). However, deviating from the environmental messaging-climate leadership trend does not automatically imply the company is trying to deceive. In fact, the low overall probability of companies releasing an environmental message possibly suggests that most companies are under-promoting their work on Twitter. As a result, this environmental messaging-climate leadership trend is valuable for assessing whether companies are generally promoting their environmental actions proportionately to their climate leadership. However, this analysis is unfit for determining what degree of messaging is generally proportionate and acceptable, which is why we have made no effort to highlight companies which may be under- or overreporting environmental messages. It is also worth noting, this model exhibited substantial sector-specific variation (high conditional $\mathrm{R}^{2}$ ), and what may be perfectly adequate environmental messaging in one sector, could be over- or under-promoting in another.

Climate leadership has increased across UK companies, which is encouraging, but not surprising given companies have already stressed willingness to adopt to more environmentally sustainable practices (Allen and Craig 2016). However, with the immediate threat of climate change (IPCC 2014), it is unclear whether the rate of growth in climate leadership is sufficient. For example, on average, companies only increased their climate score by one point every 7 years, suggesting at the current rate, it would take approximately 50 years to move from the lowest score (climate disclosure) to the highest score (climate leadership). There is already extensive guidance to support companies trying to embrace sustainability (Aggarwal and Dow 2012; Begg et al. 2018; Hoffman 2007; Ihlen 2009; Sussman and Freed 2008), as well as policy and investment tools like green finance (Leitao et al. 2021), but if the available guidance and tools have only supported the slow observed increase in climate leadership, they may not be sufficient (Ekwurzel et al. 2017). Future work could explore what mechanisms limit this growth in climate mitigation performance.

With increasing public interest in environmental issues (Leiserowitz et al. 2018; Pew Research Center, 2020), it is not surprising to see that companies have increased their environmental messaging on Twitter between 2010 and 2019. However, despite the increase, these environmental messages were still infrequent, where the average probability of a tweet containing an environmental term in 2019 was 0.03 , and only one term broadly related to the environment ('sustain') occurred in the 150 most used words. This low frequency of environmental messages was unexpected given environmental issues rank amongst the most important of consumer concerns (Pew Research Center, 2020). Whether this low frequency of environmental messaging is proportionate to public environmental messaging remains unclear, but regardless, the scarcity of environmental messages suggests that companies are prioritising other themes and more foundational work could characterise the language use and topics discussed by these companies. Furthermore, given the low frequency of environmental messages, it is plausible that there is room for companies to further promote their pro-environmental actions.

We expected increasing climate leadership would lead to stock price growth, as more of the market share is being captured by green companies (Kronthal-Sacco and Whelan, 2021), and greener companies are expected to perform better economically (El Zein et al. 2020; Zhang et al. 2019). However, in our study, change in climate leadership had no effect on stock growth, which suggests that a company's financial performance and worth are not associated with their willingness to embrace climate change mitigation actions. Further, stock growth was also not affected by change in environmental messaging, or our greenwashing index. All of this considered, we find no evidence at a macro-scale that the impact of mitigating climate change, promoting environmental actions, and representing those actions fairly has a negative or positive effect on a company's financial growth.

\subsection{Limitations and future work}

A potential limitation with this work is that our main variables (climate leadership and environmental 
messaging) may be inadequate proxies. We used climate leadership as a proxy to describe companies climate performance, i.e. emissions and attempts to reduce carbon pollution. Whilst these emissions features are captured within the CDP climate leadership score, it is unclear whether the score is completely fair, and what a fair score would look like. For example, one very large energy company was granted a high score in 2019 (B: Climate management) despite being one of the ten largest carbon emitting companies and releasing nearly $2 \%$ of the world's greenhouse gases (Ekwurzel et al. 2017). Should these extreme-emitters be granted high-scores? Should companies be rewarded with a high score for simply making efforts to mitigate carbon emissions, even if their mitigation had a negligible impact when considering their overall emissions? These are important dilemmas to address when designing climate change mitigation metrics if consumers are to make informed decisions. A further potential issue with the CDP scores, and in particular, our finding of climate leadership growth through time, is that CDP scores are derived from companies self-reporting their actions. This risks that any observed growth in climate leadership could simply be driven by companies refining the way they report themselves, albeit this is purely speculation and is unfounded.

A further limitation in our climate leadership model is the clash between constrained response data-from 1 (D-) to 8 (A) - and the non-constrained Gaussian distribution we fit the data with. This risks our predictions exceeding the natural range of the data and potentially not capturing a plateau in the climate leadership growth. To capture this relationship more accurately, it would be necessary to fit a censored-normal or beta distribution on the response and repeat the modelling, but this was undesirable in our case as these distributions are either unavailable (censorednormal) in common $\mathrm{R}$ packages or would alter important interpretation (beta) in later models, i.e. the beta coefficient could not be interpreted as a log-linear annual rate of change, which was important in Model 1-5. As such, we felt the trade-off in consistent interpretation outweighed capturing a potential plateau in climate leadership growth.

For environmental messaging, we would expect a brand's image to be mainly derived from traditional paid adverts and not corporate twitter accounts. This presents an issue, where there could be discrepancy between the company's climate leadership, the brand image consumers rely on, and a company's Twitter posts (our environmental messaging variable). A qualitative analysis to understand similarities and differences between these three components would be valuable.

An important limitation of this work is the challenge of modelling ordinal CDP climate scores. In our work, we converted the ordinal scores into integers, whereby high scores were given high values and low scores low values, e.g. A: 8 and D-: 1 . We are not the first to utilise this conversion approach (Guo et al. 2020), but given the potential issues and substantial assumptions, it is important to stress caution around interpretation of our results. The CDP scores are an important resource for monitoring environmental governance, but to really harness the impressive CDP dataset, its pivotal that analytical frameworks are established to make inference robust and representative.

A further limitation in this work is the high abundance of missing values in the climate leadership and environmental messaging data, and the risk that these values are missing with a bias (Johnson et al. 2021a; Little and Rubin, 2002). For environmental messaging, a potential bias could be that companies with more tweets (and in turn more incomplete data), are more active on social platforms, have more engaged followers, so will be more in touch with consumer concerns (e.g. the environment). As a result, with more complete data, we may expect a positive relationship between followers and environmental messaging, as well as followers and change in environmental messaging. However, the climate leadership missing data bias may be even more critical, where companies failing to disclose their climate performance may have a lower climate leadership and less growth in their climate leadershipthere is already evidence of this bias in corporate climate change disclosure data (Dawkins and Fraas, 2011). The impacts of these biases on the inferences in our study are unclear, and so our results should be interpreted cautiously and considered alongside the rest of the literature. To address these biases going forward, it is important to further encourage companies to embrace climate change disclosure, improving our understanding of how climate performance is changing on a larger scale. Further, and perhaps more importantly, as companies' social responsibility improves with reporting (Luo and Tang, 2014), wholesale uptake of reporting, and a more a general shift towards increased transparency could have substantial benefits for mitigating carbon emissions. Companies themselves may also benefit from increased reporting with evidence suggesting that engaging in the CDP is associated with improved financial performance (Alsaifi et al. 2020), although the mechanisms behind this association are unclear.

An exciting area for future work could be to explore the role of temporal correlations and lags between our three main data sources: climate leadership, environmental messaging, and stock performance. Within our work, we coarsened our variables down to annual metrics, but in future work, there is the possibility to explore volatility at a fine temporal resolution. 


\subsection{Concluding remarks}

The growth in climate leadership is encouraging and suggests that UK companies are eager to mitigate their carbon outputs. However, the current rate of growth could be insufficient, and calls from companies for policymakers to provide clear guidance on mitigation steps remain essential (Allen and Craig, 2016). Similarly, the growth in environmental messaging shows that companies are aware of the public's desire for more sustainable products, and encouragingly, we found evidence that environmental messaging is generally aligned with climate leadership performance, i.e. there is no clear widescale evidence of using Twitter to greenwash in the studied UK companies. However, that is not to say that the practice of greenwashing does not occur within some UK companies and emphasises the need for better metrics to understand the climate impacts of companies. This would allow consumers to make more informed choices about which businesses they patronise, potentially driving companies to further implement environmental changes.

Supplementary InformationThe online version contains supplementary material available at https://doi.org/10.1007/s40974021-00237-y.

Acknowledgements Thanks to CDP, Twitter, and the Yahoo-London Stock Exchange for making data available. Thanks to Dr Luke Evans and seven reviewers for valuable feedback. This work was funded by a NERC (Natural Environment Research Council) Centre for Doctoral Training studentship (NE/P012345/1).

Author contributions TFJ developed the ideas, TFJ and MPG collected the data, TFJ analysed the data, and wrote the manuscript. MPG critiqued the ideas and contributed critically to a draft of the work.

Funding This work was funded by a NERC (Natural Environment Research Council) Centre for Doctoral Training studentship (NE/ P012345/1).

Data availability The CDP and Twitter data are protected and so cannot be shared, but both can be sourced independently (CDP: https://www.cdp.net/en/companies/companies-scores; Twitter: https:// github.com/ropensci/rtweet). Code is available at https://doi.org/10. 5281/zenodo.5844898 and https://github.com/GitTFJ/greenwashing_ eee.

\section{Declarations}

Competing interests Authors have no competing interests or conflicts of interest.

Ethics approval Research met the University of Reading's institutional ethics guidelines (where the work was conducted) with all data in the public domain. We opted to preserve companies' anonymity.

Open Access This article is licensed under a Creative Commons Attribution 4.0 International License, which permits use, sharing, adaptation, distribution and reproduction in any medium or format, as long as you give appropriate credit to the original author(s) and the source, provide a link to the Creative Commons licence, and indicate if changes were made. The images or other third party material in this article are included in the article's Creative Commons licence, unless indicated otherwise in a credit line to the material. If material is not included in the article's Creative Commons licence and your intended use is not permitted by statutory regulation or exceeds the permitted use, you will need to obtain permission directly from the copyright holder. To view a copy of this licence, visit http://creativecommons. org/licenses/by/4.0/.

\section{References}

Aggarwal R, Dow S (2012) Corporate governance and business strategies for climate change and environmental mitigation. J Finance Eur. https://doi.org/10.1080/1351847X.2011.579745

Albarrak MS, Elnahass M, Salama A (2019) The effect of carbon dissemination on cost of equity. Bus Strategy Environ 28:1179-1198. https://doi.org/10.1002/bse.2310

Allen MW, Craig CA (2016) Rethinking corporate social responsibility in the age of climate change: a communication perspective. Int J Corp Soc Responsib. https://doi.org/10.1186/s40991-0160002-8

Alsaifi K, Elnahass M, Salama A (2020) Carbon disclosure and financial performance: UK environmental policy. Bus Strategy Environ 29:711-726. https://doi.org/10.1002/bse.2426

Bansal P, Roth K (2000) Why companies go green: a model of ecological responsiveness. Acad Manage J 43:717-736. https:// doi.org/10.2307/1556363

Begg K, van der Woerd F, Levy D (2018) The business of climate change: corporate responses to Kyoto, the business of climate change: corporate responses to Kyoto. doi:https://doi.org/10. 4324/9781351281683

Bonini SMJ, Hintz G, Mendonca LT (2008) Addressing consumer concerns about climate change. McKinsey Q

Bosello F, Roson R, Tol RSJ (2006) Economy-wide estimates of the implications of climate change: human health. Ecol Econ 58:579-591. https://doi.org/10.1016/j.ecolecon.2005.07.032

Brulle RJ, Aronczyk M, Carmichael J (2020) Corporate promotion and climate change: an analysis of key variables affecting advertising spending by major oil corporations, 1986-2015. Clim Change. https://doi.org/10.1007/s10584-019-02582-8

CDP (2020) Companies scores [WWW Document]. URL https:// www.cdp.net/en/companies/companies-scores. Accessed $11 \mathrm{Feb}$ 2020

Dawkins C, Fraas JW (2011) Coming clean: the impact of environmental performance and visibility on corporate climate change disclosure. J Bus Ethics. https://doi.org/10.1007/s10551-0100681-0

de Freitas Netto SV, Sobral MFF, Ribeiro ARB, Soares GRdaL (2020) Concepts and forms of greenwashing: a systematic review. Environ Sci Eur 32:19. https://doi.org/10.1186/s12302020-0300-3

European Commission (2021) Screening of websites [WWW Document]. Eur. Comm. url: https://ec.europa.eu/commission/press corner/detail/en/ip_21_269. Accessed 8 April 21

de Jong MDT, Huluba G, Beldad AD (2020) Different shades of greenwashing: consumers' reactions to environmental lies, halflies, and organizations taking credit for following legal obligations. J Bus Tech Commun 34:38-76. https://doi.org/10.1177/ 1050651919874105

Ekwurzel B, Boneham J, Dalton MW, Heede R, Mera RJ, Allen MR, Frumhoff PC (2017) The rise in global atmospheric CO2, surface temperature, and sea level from emissions traced to major carbon 
producers. Clim Change. https://doi.org/10.1007/s10584-0171978-0

El Zein SA, Consolacion-Segura C, Huertas-Garcia R (2020) The role of sustainability in brand equity value in the financial sector. Sustain Switz. https://doi.org/10.3390/su12010254

Ertz M, Huang R, Jo MS, Karakas F, Sarigöllü E (2017) From singleuse to multi-use: study of consumers' behavior toward consumption of reusable containers. J Environ Manage. https://doi. org/10.1016/j.jenvman.2017.01.060

Fadul J, Maurer RA (2004) Business ethics, corporate social responsibility, and firm value in the oil and gas industry. In: Proceedings-SPE annual technical conference and exhibition. Doi:https://doi.org/10.2523/90701-ms

Feinerer I, Hornik K (2019) tm: Text mining Package

Gilmore AB, Fooks G, Drope J, Bialous SA, Jackson RR (2015) Exposing and addressing tobacco industry conduct in lowincome and middle-income countries. The Lancet. https://doi. org/10.1016/S0140-6736(15)60312-9

Gov (2008) Consumer protection from unfair trading regulations

Guo T, Zha G, Lee CL, Tang Q (2020) Does corporate green ranking reflect carbon-mitigation performance? J Clean Prod 277:123601. https://doi.org/10.1016/j.jclepro.2020.123601

Han H, Ahn SW (2020) Youth mobilization to stop global climate change: narratives and impact. Sustainability 12:4127. https:// doi.org/10.3390/su12104127

Hoffman AJ (2007) Carbon strategies: how leading companies are reducing their climate change footprint. University of Michigan Press, New York

Houghton JT, Jenkins GJ, Ephraums JJ (1990) Climate change: the IPCC scientific assessment. Clim Change IPCC Sci Assess. https://doi.org/10.1016/0167-8809(92)90191-d

Ihlen $\varnothing$ (2009) Business and climate change: the climate response of the world's 30 largest corporations. Environ Commun. https:// doi.org/10.1080/17524030902916632

International Energy Agency (2019) Global EV Outlook 2019

IPBES (2019) Summary for policymakers of the global assessment report on biodiversity and ecosystem services of the Intergovernmental Science-Policy Platform on Biodiversity and Ecosystem Services.

IPCC (2014) Climate Change 2014: Synthesis Report. Contribution of Working Groups I, II and III to the fifth assessment report of the intergovernmental panel on climate Change, IPCC

Johnson TF, Isaac NJB, Paviolo A, González-Suárez M (2021a) Handling missing values in trait data. Glob Ecol Biogeogr. https://doi.org/10.1111/geb.13185

Johnson TF, Kent H, Hill BM, Dunn G, Dommett L, Penwill N, Francis T, González-Suárez M (2021b) classecol: Classifiers to understand public opinions of nature. Methods Ecol Evol 12:1329-1334. https://doi.org/10.1111/2041-210X.13596

Kearney MW (2017) rtweet: collecting twitter data

Kronthal-Sacco R, Whelan T (2021) Sustainable Market Share Index ${ }^{\mathrm{TM}} 38$

Leiserowitz A, Maibach E, Roser-Renouf C, Rosenthal S, Cutler M, Kotcher J (2018) Climate change in the American mind: March
2018, Yale University and George Mason University. Yale Program on Climate Change Communication, New Haven, CT

Leitao J, Ferreira J, Santibanez-Gonzalez E (2021) Green bonds, sustainable development and environmental policy in the European Union carbon market. Bus Strategy Environ 30:2077-2090. https://doi.org/10.1002/bse.2733

Little RJA, Rubin DB (2002) Statistical analysis with missing data, statistical analysis with missing data, 2nd edn. Wiley, Hoboken. https://doi.org/10.2307/1533221

Luo L, Tang Q (2014) Does voluntary carbon disclosure reflect underlying carbon performance? J Contemp Account Econ 10:191-205. https://doi.org/10.1016/j.jcae.2014.08.003

Perlin M (2020) BatchGetSymbols: downloads and organizes financial data for multiple tickers

Pew Research Center (2020) As economic concerns recede, environmental protection rises on the public's Policy Agend

Ren21 (2019) Renewables 2019 Global Status Report

Ripple WJ, Wolf C, Newsome TM, Galetti M, Alamgir M, Crist E, Mahmoud MI, Laurance WF (2017) World scientists' warning to humanity: a second notice. Bioscience 67:1026-1028. https:// doi.org/10.1093/biosci/bix125

Rockström J, Steffen W, Noone K, Persson Å, Chapin FS, Lambin EF, Lenton TM, Scheffer M, Folke C, Schellnhuber HJ, Nykvist B, De Wit CA, Hughes T, Van Der Leeuw S, Rodhe H, Sörlin S, Snyder PK, Costanza R, Svedin U, Falkenmark M, Karlberg L, Corell RW, Fabry VJ, Hansen J, Walker B, Liverman D, Richardson K, Crutzen P, Foley JA (2009) A safe operating space for humanity. Nature. https://doi.org/10.1038/461472a

Stern PC (2000) New environmental theories: toward a coherent theory of environmentally significant behavior. J Soc Issues 56:407-424. https://doi.org/10.1111/0022-4537.00175

Sussman FG, Freed JR (2008) Adapting to climate change: a business approach. Environment

United Nations (2018) Sustainable Development Goals I UNDP

Wagner M, Schaltegger S (2004) The effect of corporate environmental strategy choice and environmental performance on competitiveness and economic performance: an empirical study of EU manufacturing. Eur Manag J. https://doi.org/10.1016/j. emj.2004.09.013

Wedari LK, Jubb C, Moradi-Motlagh A (2021) Corporate climaterelated voluntary disclosures: Does potential greenwash exist among Australian high emitters reports? Bus Strategy Environ. https://doi.org/10.1002/bse.2836

White K, Habib R, Hardisty DJ (2019) How to SHIFT consumer behaviors to be more sustainable: a literature review and guiding framework. J Mark 83:22-49. https://doi.org/10.1177/ 0022242919825649

Zhang D, Rong Z, Ji Q (2019) Green innovation and firm performance: evidence from listed companies in China. Resour Conserv Recycl 144:48-55. https://doi.org/10.1016/j.resconrec. 2019.01.023 